
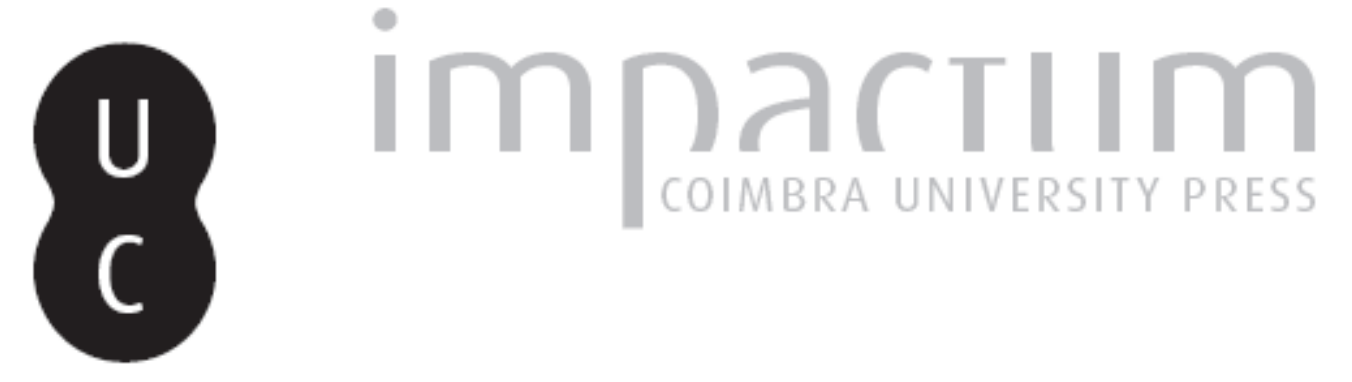

\title{
[Recensão a] Michael Blauberger - Staatliche Beihilfen in Europa: die integration der Beihilfekontrolle in der EU und die Europäisierung der Beihilfepolitik in den neuen Mitgliedstaaten
}
Autor(es):
Almeida, João José Nogueira de
Publicado por: Faculdade de Direito da Universidade de Coimbra
URL
persistente:
URI:http://hdl.handle.net/10316.2/24718
DOI:
http://dx.doi.org/10.14195/0870-4260_53_7

\section{Accessed : $\quad$ 26-Apr-2023 12:30:28}

A navegação consulta e descarregamento dos títulos inseridos nas Bibliotecas Digitais UC Digitalis, UC Pombalina e UC Impactum, pressupõem a aceitação plena e sem reservas dos Termos e Condições de Uso destas Bibliotecas Digitais, disponíveis em https://digitalis.uc.pt/pt-pt/termos.

Conforme exposto nos referidos Termos e Condições de Uso, o descarregamento de títulos de acesso restrito requer uma licença válida de autorização devendo o utilizador aceder ao(s) documento(s) a partir de um endereço de IP da instituição detentora da supramencionada licença.

Ao utilizador é apenas permitido o descarregamento para uso pessoal, pelo que o emprego do(s) título(s) descarregado(s) para outro fim, designadamente comercial, carece de autorização do respetivo autor ou editor da obra.

Na medida em que todas as obras da UC Digitalis se encontram protegidas pelo Código do Direito de Autor e Direitos Conexos e demais legislação aplicável, toda a cópia, parcial ou total, deste documento, nos casos em que é legalmente admitida, deverá conter ou fazer-se acompanhar por este aviso.

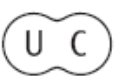




\section{UNIVERSIDADE DE COIMBRA \\ FACULDADE DE DIREITO}

BOLETIII DE CÊACCLS ECONÓNCACAS

VOLUME LIII

$\begin{array}{llll}2 & 0 & 1 & 0\end{array}$

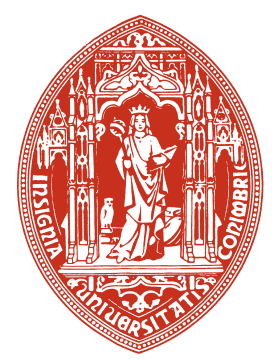

COIMBRA 


\section{Recensão}

Michael Blauberger, Staatliche Beihilfen in Europa - Die Integration der Beihilfekontrolle in der EU und die Europäisierung der Beihilfepolitik in den neuen Mitgliedstaaten, VS Verlag für Sozialwissenschaften, 218 pp.

Em 2009, deu à estampa na editora VS Verlag für Sozialwissenschaften, a tese de doutoramento de Michael Blauberger sob o título Staatliche Beihilfen in Europa - Die Integration der Beihilfekontrolle in der EU und die Europäisierung der Beihilfepolitik in den neuen Mitgliedstaaten. Trata-se de uma tese de doutoramento relativamente curta, com cerca de 218 páginas, escrita em alemão, que versa especificamente sobre a questão da progressiva europeização da política dos auxílios de Estado.

O Tratado sobre o Funcionamento da União Europeia (TFUE) prevê nos artigos $107 .^{\circ}$ a $108 .^{\circ}$ um regime de controlo dos auxílios que segue no fundamental o modelo adoptado no Tratado de Roma, no qual se prevê o estabelecimento de uma proibição de princípio dos auxílios (art. 107. ${ }^{\circ}$, n. ${ }^{\circ} 1$ ), admitindo-se apenas excepcionalmente a sua compatibilidade com o mercado interno ou único (art. 107. ${ }^{\circ}$, n. $^{\circ} 2$ e n. ${ }^{\circ}$ 3). A aplicação da proibição geral dos auxílios, bem como as decisões acerca da compatibilidade dos mesmos com o mercado único pertencem no essencial à Comissão, que actua de forma independente dos Estados. O controlo dos auxílios sofreu ao longo dos anos uma evolução que não foi antecipada nem querida pelos Estados membros. Originalmente o controlo dos auxílios tinha uma natureza essencialmente política 
e negativa. Gradualmente e muito por causa do empenho da Comissão o controlo dos auxílios foi-se transformando. Os traços originais do controlo dos auxílios foram-se esbatendo, assumindo o controlo actualmente uma dimensão jurídica e positiva cada vez intensa. Com a progressiva transformação do controlo dos auxílios num direito dos auxílios de Estado e num direito dos auxílios de Estado relativamente perfeito, o não cumprimento deixou de ser uma opção inócua para os Estados. O não cumprimento ou a ignorância do direito dos auxílios passou a ter consequências pesadas, que vão muito para lá dos efeitos isolados de uma eventual decisão negativa da Comissão a propósito de um auxílio, pondo em causa toda a política de fomento material das actividades económicas dos poderes públicos dos Estados-membros. Os Estados-membros já não podem dar-se ao luxo de não cumprir ou de ignorar o direito dos auxílios de Estado. Consequentemente, estando o direito dos auxílios já devidamente apetrechado em termos de procedimentos de controlo e de sanções, a questão política relevante deixou de ser a possibilidade, ou não, de ser efectivamente aplicado e cumprido pelos Estados-membros. A existência de um direito dos auxílios dotado de efectividade aumentou enormemente a importância, não só do seu próprio conteúdo material, mas também do órgão ou órgãos competentes, tanto no que toca à criação de normas, como no que diz respeito à sua implementação.

É neste contexto que a Comissão, tirando partido da relativa imprecisão das normas materiais do artigo $107 .^{\circ}$ e da diversidade de preferências manifestada pelos Estados-membros quanto aos auxílios compatíveis com o mercado interno, tem vindo, ao longo dos anos, a determinar positivamente de forma crescente o conteúdo dos auxílios, primeiro na forma de soft law, depois na forma de hard law. Na medida em que a Comissão define positivamente o conteúdo material dos auxílios diminui do mesmo passo a autonomia dos Estados-membros na escolha dos objectivos e dos instrumentos das políticas selectivas nacionais de subvencionamento. Face ao disposto no TFUE relativamente aos auxílios de Estado é todavia no mínimo questionável que a Comissão tenha o poder de definir materialmente o conteúdo dos auxílios que os Estados podem conceder ao abrigo do artigo 107. ${ }^{\circ}$. 
É este, em suma, o universo de problemas em que se move a tese de Blauberger, que está organizada à boa e eficiente maneira alemã da seguinte forma: Introdução, Corpo Principal e Conclusão.

$\mathrm{Na}$ Introdução, Blauberger faz o "estado da arte» e põe em relevo a necessidade, a premência e a actualidade da investigação a que se propõe e circunscreve o objecto do seu trabalho.

O corpo principal está dividido em duas partes. Na primeira parte, quanto a nós a mais interessante e de maior valia científica, Blauberger analisa em primeiro lugar, a progressiva transformação do controlo dos auxílios, de um controlo político não vinculante num controlo jurídico «perfeito» e em segundo lugar, a progressiva determinação material do próprio conteúdo dos auxílios pela Comissão que vem assim impondo aos Estados as suas próprias pré-comprensões ideológicas disfarçadas numa análise económica dos auxílios, que à boleia da "more economic approach» vêm fazendo caminho, «roubando» desta forma a Comissão aos Estados as competências que estes supunham ter em exclusivo de determinação das suas políticas de subvencionamento.

$\mathrm{Na}$ segunda parte, Blauberger analisa a forma como estes processos de transformação da natureza do controlo dos auxílios decorreram na prática nos novos Estados membros, em particular na Polónia e na República Checa, pondo em relevo a europeização verificada nas políticas de subvencionamento particulares de cada um deles. A europeização das políticas de auxílios, quer da Polónia, quer da República Checa, consistiu no essencial num processo de uniformização das preferências nacionais de cada um destes países, a favor de uma visão europeia da política de auxílios, na definição da qual a Comissão tem um papel praticamente exclusivo.

$\mathrm{Na}$ terceira parte, a Conclusão, o autor apresenta as suas reflexões finais. A progressiva determinação pela Comissão das políticas de auxílios nacionais exigem uma legitimação clara que aquela tem procurado, de forma não muito convincente, na «more economic approach", buscando a legitimação dos auxílios no objectivo da eficiência económica e na maximização do bem-estar económico agregado ao nível da União. Contudo, a dimensão redistributiva dos auxílios torna necessária e mesmo imprescindível a 
concepção de novas formas de participação dos Estados na determinação positiva da política de auxílios, em contraposição do papel crescente que a Comissão tem vindo a ganhar na definição material das políticas de auxílios. Infelizmente, como de resto conclui Blauberger, tal não foi ainda feito.

João José Nogueira de Almeida Faculdade de Direito da Universidade de Coimbra 